\title{
Prevalence of thrombocytopenia before and after initiation of HAART among HIV infected patients at black lion specialized hospital, Addis Ababa, Ethiopia: a cross sectional study
}

Gashaw Garedew Woldeamanuel ${ }^{1 *}$ and Diresibachew Haile Wondimu²

\begin{abstract}
Background: Hematological abnormalities are common in HIV positive patients. Of these, thrombocytopenia is a known complication which has been associated with a variety of bleeding disorders. However, its magnitude and related factors have not been well-characterized in the era of highly active antiretroviral therapy (HAART) in Ethiopia. Therefore, this study aimed to assess the prevalence of thrombocytopenia before and after initiation of HAART among HIV positive patients attending Black Lion Specialized Hospital, Addis Ababa, Ethiopia.
\end{abstract}

Methods: A cross sectional study was conducted from February to April 2017 in Black Lion Specialized Hospital, Addis Ababa, Ethiopia. A total of 176 patients on HAART were selected using simple random sampling techniques. Socio-demographic and clinical characteristics of the study patients were collected using structured questionnaire. Measurements of platelet counts and CD4 + T cell counts were made using Sysmex XT 2000i hematology analyzer and BD FACS Count CD4 analyzer, respectively. Statistical analysis of the data (Paired T- test and binary logistic regression) was done using SPSS version 20. $P$-value $<0.05$ was considered as statistically significant.

Results: A total of 176 patients (Age $>18$ years old) were enrolled in this study and had a mean age of $40.08 \pm$ 9.38 years. There was significant increase in the mean values of platelet counts $\left(218.44 \pm 106.6 \times 10^{3} / \mu \mathrm{l}\right.$ vs $273.65 \pm 83.8 \times$ $\left.10^{3} / \mu \mathrm{l}, p<0.001\right)$ after six months of HAART initiation compared to the baseline. Prevalence of thrombocytopenia before and after HAART initiation was 25 and 5.7\% respectively. HIV patients whose CD4 counts $<200$ Cells/ $\mu$ l were more likely to have thrombocytopenia than HIV patients whose CD4 count $\geq 350$ Cells/ $\mu$. However, it was not statistically associated with prevalence of thrombocytopenia.

Conclusions: This study has shown that the prevalence of thrombocytopenia after HAART initiation was decreased significantly. Based on our results, a number of study participants still had thrombocytopenia after initiation of HAART. Therefore, continuous screening for thrombocytopenia among HIV infected patients should be performed to decrease the risk of morbidity and mortality.

Keywords: HIV, HAART, Thrombocytopenia, Ethiopia

\footnotetext{
* Correspondence: gashawgaredew05@gmail.com

${ }^{1}$ Department of Medicine, College of Medicine and Health Sciences, Wolkite

University, Ethiopia, P.O. Box 07, Wolkite, Ethiopia

Full list of author information is available at the end of the article
}

(c) The Author(s). 2018 Open Access This article is distributed under the terms of the Creative Commons Attribution 4.0 International License (http://creativecommons.org/licenses/by/4.0/), which permits unrestricted use, distribution, and reproduction in any medium, provided you give appropriate credit to the original author(s) and the source, provide a link to the Creative Commons license, and indicate if changes were made. The Creative Commons Public Domain Dedication waiver (http://creativecommons.org/publicdomain/zero/1.0/) applies to the data made available in this article, unless otherwise stated. 


\section{Background}

Thrombocytopenia is a frequent hematologic disorder in patients infected with the human immunodeficiency virus (HIV) [1]. It can occur independently of other cytopenias and at all stages of HIV infection [2]. Although often asymptomatic, the thrombocytopenia in these patients may be associated with a serious complication including major bleeding and death [3]. It is a frequent disorder occurring in about $30-40 \%$ of individuals with HIV infection [4]. Thrombocytopenia may indicate the initial manifestation of HIV diseases and it may enhance the progress of the disease into AIDS or advanced immunological deterioration [5].

The underlying mechanisms for the development of thrombocytopenia has not yet been well described [6]. The suggested mechanisms that may account for the development thrombocytopenia includes; increased destruction of platelets due to the presence of anti-platelet antibodies, and direct infection of megakaryocytes by HIV leading to low production of platelets from those precursor cells [6].

Multicenter AIDS cohort study was conducted in Asia, America and Africa [7]. The result showed that the average frequencies of thrombocytopenia at initiation of antiretroviral therapy were $7 \%$ and varied by country [7]. For instance, a study conducted in India showed that the prevalence of thrombocytopenia before initiation of Zidovudine was $16.6 \%$ which rises to $30 \%$ after initiation of Zidovidine. It was suggested mechanistically that immune mediated destruction of both platelets and megakaryocytes occurs in Zidovudine therapy [8].

The prevalence of thrombocytopenia showed an increasing trend with decreasing CD4 count $[6,9]$ but, the prevalence of thrombocytopenia did not differ by sex, ethnicity or age [9]. A study conducted in Uganda also reported that the prevalence of thrombocytopenia was $17.8 \%$ among HAART naive and was $13.0 \%$ for clients who were on ART for up to 6 months. The study found a significant association between thrombocytopenia and other cytopenias, $\mathrm{CD}^{+} \mathrm{T}$ cell counts, antiretroviral treatment(ART), and deteriorating HIV stage [10].

A comparative cross sectional study carried out at Gondar University hospital, Ethiopia showed that the prevalence of thrombocytopenia was 9\% in HAART naïve patients and $4.1 \%$ in patients on HAART [11].

Although cytopenias have been widely reported in HIV infection, there is little data regarding prevalence and associated factors of thrombocytopenia among HIV infected patients before and after initiation of HAART in Ethiopia. This study will provide further information and it can serve as a reference material for further researches with regards to HIV related thrombocytopenia. The aim of this study was therefore to determine the prevalence of thrombocytopenia before and after initiation of antiretroviral therapy among HIV patients who attended at ART clinic of Black Lion Specialized Hospital, Addis Ababa, Ethiopia.

\section{Methods}

The methodological approach of this study is summarized based on previous study [12]. Institution based cross sectional study design was conducted in Black Lion Specialized Hospital, Addis Ababa, Ethiopia from February to April 2017. During the data collection period, a total 2675 HIV infected adults were on ART, of which 176 HIV infected patients taking HAART for at least six months were selected randomly. Sample size was determined using a statistical formula for single population proportion $\left(n=\mathrm{Z}^{2} \mathrm{p}(1-\mathrm{p}) / \mathrm{d}^{2}\right)$, taking $p=12.7 \%$ (prevalence rate of thrombocytopenia from previous study) [4], 5\% level of precision (d) with 95\% confidence interval. Pregnant women, patients transferred from other health institutions, diagnosed as having hematological diseases, severely sick due to other medical conditions and those who took other medication were excluded from the study.

The structured questionnaire was adapted (see additional file 1) after the review of different literatures and the data was collected by trained ART nurses. Data concerning socio-demographic, clinical characteristics and pre ART information of the study participants were collected by interviewer administered questionnaire and review of medical records. Then, blood sample was collected and sent to the hematology laboratory. Based on the standard procedures, platelet counts and CD4+ $\mathrm{T}$ cell counts were determined using Sysmex XT 2000i hematology analyzer and BD FACS Count System respectively.

To maintain good quality of the data; standard procedures were followed during all laboratory procedures and the quality of CD4 and hematology analyzer were checked by running quality control samples along the patients sample.

Additionally, there was training of data collectors, pre testing of questionnaires and the data collection process were supervised in daily fashion.

Thrombocytopenia was defined as platelet counts less than 150,000cells $/ \mu \mathrm{l}$. It was further classified into mild $\left(100,000-150,000 / \mathrm{mm}^{3}\right)$, moderate $\left(50,000 / \mathrm{mm}^{3}-\right.$ $100,000 / \mathrm{mm}^{3}$ ) and severe thrombocytopenia (platelet counts $<50,000 / \mathrm{mm}^{3}$ ). The data were coded, checked and entered into SPSS version 20 for analysis. Descriptive statistics (mean and standard deviation) were used for continuous variables in the course of analysis. To assess the association between dependent variables and independent variables, logistic regression was done. A $p$-value of $<0.05$ was considered to be statistically significant.

\section{Result}

General characteristics of study participants

A total of 176 HIV positive patients, of which 107(60.8\%) women and 69(39.2\%) men were involved in this study. The mean age of the patients were $40.08 \pm 9.38$ years, 
ranging from 20 to 62 years. The majority of study participants were within the WHO stage III category at the baseline. The most widely used HAART regimen in this study was 1e (TDF-3TC-EFV) (Table 1).

\section{Platelets and $\mathrm{CD}^{+} \mathrm{T}$ cell counts of study participants}

The mean platelet count of the study participants were $218.44 \pm 106.6 \times 10^{3} / \mu \mathrm{l}$ at the baseline and $273.65 \pm 83.8 \times$ $10^{3} / \mu \mathrm{l}$ after HAART initiation $(p<0.001)$. Similarly, the mean CD4+ T cell counts showed an increment from $162.35 \pm 113.2 \mathrm{cells} / \mu \mathrm{l}$ at the baseline to $360.76 \pm 196.2$ cells/ $\mu$ l after HAART initiation $(p<0.001)$.

Table 1 Socio-demographic and clinical characteristics of HIV positive patients taking HAART at Black Lion Specialized Hospital, Addis Ababa, Ethiopia, 2017

\begin{tabular}{|c|c|c|}
\hline Variables & Frequency $(n=176)$ & Percentage (\%) \\
\hline \multicolumn{3}{|l|}{ Age (in years) } \\
\hline $20-29$ & 28 & 15.9 \\
\hline $30-39$ & 58 & 33 \\
\hline $40-49$ & 61 & 34.7 \\
\hline $50-59$ & 26 & 14.8 \\
\hline $60-69$ & 3 & 1.7 \\
\hline \multicolumn{3}{|l|}{ Sex } \\
\hline Male & 69 & 39.2 \\
\hline Female & 107 & 60.8 \\
\hline \multicolumn{3}{|l|}{ Marital Status } \\
\hline Single & 50 & 28.4 \\
\hline Divorced & 24 & 13.6 \\
\hline Married & 75 & 42.6 \\
\hline Widowed & 27 & 15.3 \\
\hline \multicolumn{3}{|l|}{ Educational status } \\
\hline illiterate & 21 & 11.9 \\
\hline Primary school & 74 & 42 \\
\hline High school & 62 & 35.2 \\
\hline Certificate and above & 19 & 10.8 \\
\hline \multicolumn{3}{|c|}{ WHO clinical stages at the baseline } \\
\hline Stage I & 32 & 18.2 \\
\hline Stage II & 39 & 22.2 \\
\hline Stage III & 59 & 33.5 \\
\hline Stage IV & 46 & 26.1 \\
\hline \multicolumn{3}{|l|}{ Types of ART regimens } \\
\hline $1 \mathrm{c}$ & 30 & 17 \\
\hline $1 d$ & 40 & 22.7 \\
\hline $1 e$ & 94 & 53.4 \\
\hline $1 f$ & 12 & 6.8 \\
\hline
\end{tabular}

Note: $1 \mathrm{c}=$ AZT-3TC-NVP, $1 \mathrm{~d}=$ AZT-3TC-EFV, $1 \mathrm{e}=$ TDF-3TC-EFV, $1 \mathrm{f}=$ TDF-3TC-NVP
Prevalence of thrombocytopenia and associated factors before HAART initiation

The prevalence of thrombocytopenia was $25 \%$ before HAART initiation. From the total thrombocytopenic subjects at the baseline, 54.6, 31.8 and 13.6\% had mild, moderate and severe thrombocytopenia, respectively (Fig. 1). The overall prevalence of thrombocytopenia was $26.1 \%$ among males and $24.3 \%$ among females. However, the difference was not statistically significant. In this study, the majority of thrombocytopenia cases (31\%) were observed in the aged subjects ( $\geq 50$ years). HIV patients whose CD4 counts less than 200 cells $/ \mathrm{mm}^{3}$ were 4.4 times more likely to have thrombocytopenia than HIV patients whose CD4 counts greater than or equals to 350 cells $/ \mathrm{mm}^{3}$ (Table 2).

\section{Prevalence of thrombocytopenia and associated factors after HAART initiation}

The prevalence of thrombocytopenia was 5.7\% after HAART initiation, of which $90 \%$ had mild and $10 \%$ had moderate thrombocytopenia (fig. 1). The prevalence of thrombocytopenia after HAART initiation was significantly decreased by $19.3 \%(P<0.001)$. From thrombocytopenic patients after HAART initiation, about $10.1 \%$ were males and $2.8 \%$ were females. The prevalence of thrombocytopenia was higher (10.3\%) among patients whose age group was $\geq 50$ years. HIV patients on AZT based therapy were more likely to have thrombocytopenia than HIV patients on TDF based therapy. Increased percentage of thrombocytopenia were observed in HIV patients whose CD4 count was $<200$ cells $/ \mu$ l $(P<0.05)$, but there was no significant association in the thrombocytopenia between patients who were categorized in to different $\mathrm{CD} 4$ count categories $(P>0.05)$ (Table 3$)$.

\section{Discussion}

It's well documented that hematological abnormalities are common in HIV infected patients [2]. Thrombocytopenia, for instance, is a condition frequently seen in HIV infected individuals regardless of HIV status, gender, or age. Consequently, it's tempting to deduce that the presence of thrombocytopenia is associated with rapid disease progression, and by complicating the management of AIDS patients, thrombocytopenia has become a medical challenge [13].

This study revealed that the prevalence of thrombocytopenia was $25 \%$ at baseline and $5.7 \%$ after six months of HAART initiation. A study conducted in Uganda reported that the prevalence of thrombocytopenia was $17.8 \%$ among antiretroviral HAART-naive and was $13.0 \%$ for clients who were on ART for up to 6 months [10]. Another study conducted in Ethiopia reported that the prevalence of thrombocytopenia was $4.1 \%$ in patients on HAART and 9\% in HAART naive patients [11]. The 


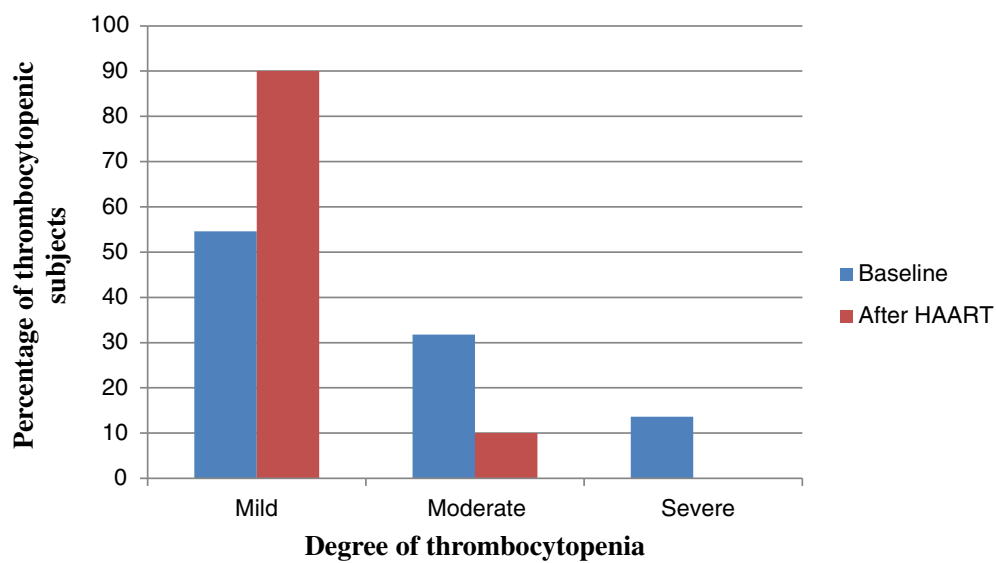

Fig. 1 Degree of thrombocytopenia among HIV positive adult patients at baseline and after six months of HAART initiation at Black Lion Specialized Hospital, Addis Ababa, Ethiopia, 2017

difference in results seen from the present study might be due to the difference in the definition of thrombocytopenia, study design and size of the study population.

The decrease in the prevalence of thrombocytopenia after HAART initiation might be due to; disorders of hematopoiesis, opportunistic infections and immune causes related to HIV leading to low platelets count could be reverted after HAART initiation [14]. Additionally the presence of intervention protocol for HIV subjects will decrease the incidence of thrombocytopenia [13].

The study found that older age (age $>50$ years) was a risk factor for thrombocytopenia, In Lai et al.'s study, for every

Table 2 Thrombocytopenia and its associated factors before HAART initiation in HIV positive patients attending Black Lion Specialized Hospital, Addis Ababa, Ethiopia, 2017

\begin{tabular}{|c|c|c|c|c|}
\hline \multirow[t]{2}{*}{ Variables } & \multicolumn{2}{|c|}{ Thrombocytopenia } & \multirow{2}{*}{$\begin{array}{l}\text { Adjusted } \\
\text { OR(95\%Cl) }\end{array}$} & \multirow[t]{2}{*}{$P$ value } \\
\hline & Yes (\%) & No (\%) & & \\
\hline \multicolumn{5}{|l|}{ Age(in years) } \\
\hline $20-29$ & $3(10.7 \%)$ & $25(89.3 \%)$ & $0.3(0.07-1.24)$ & \\
\hline $30-39$ & $14(24.1 \%)$ & $44(75.9 \%)$ & $0.7(0.26-1.97)$ & 0.45 \\
\hline $40-49$ & 18(29.5\%) & $43(70.5 \%)$ & $0.9(0.34-2.40)$ & \\
\hline$\geq 50$ & $9(31 \%)$ & $20(69 \%)$ & 1 & \\
\hline \multicolumn{5}{|l|}{ Sex } \\
\hline Female & $26(24.3 \%)$ & $81(75.7 \%)$ & $0.9(0.47-1.99)$ & 0.93 \\
\hline Male & 18(26.1\%) & $51(73.9 \%)$ & 1 & \\
\hline \multicolumn{5}{|c|}{ WHO clinical stage } \\
\hline Stage III/IV & $27(25.7 \%)$ & $78(74.3 \%)$ & $1.1(0.54-2.34)$ & 0.76 \\
\hline Stage $|/| \mid$ & 17(23.9\%) & $54(76.1 \%)$ & 1 & \\
\hline \multicolumn{5}{|c|}{ CD4 count (cells/mm³) } \\
\hline$<200$ & $34(28.9 \%)$ & $88(72.1 \%)$ & $4.4(0.52-36.28)$ & 0.35 \\
\hline $200-349$ & $9(22.5 \%)$ & $31(77.5 \%)$ & $3.3(0.37-29.84)$ & \\
\hline$\geq 350$ & $1(7.1 \%)$ & 13(92.9\%) & 1 & \\
\hline
\end{tabular}

1-year increase in age, the prevalence of thrombocytopenia increased by 1.04 fold [15]. The increase in the prevalence of thrombocytopenia with age might be due to a higher incidence of myelodysplasia in older patients [15]. However, thrombocytopenia had not showed statistical significance difference with sex and age. This was in agreement with previous studies $[9,16]$.

According to the present study, the prevalence of thrombocytopenia was increased with decreasing CD4 count both before and after HARRT initiation. Thrombocytopenia was more prevalent among HIV positive patients who had a CD $4+\mathrm{T}$ cell count of $<200$ cells $/ \mu \mathrm{l}$.

Table 3 Thrombocytopenia and its associated factors after HAART initiation in HIV positive patients attending Black Lion Specialized Hospital, Addis Ababa, Ethiopia, 2017

\begin{tabular}{|c|c|c|c|c|}
\hline \multirow[t]{2}{*}{ Variables } & \multicolumn{2}{|c|}{ Thrombocytopenia } & \multirow[t]{2}{*}{ Adjusted OR(95\%Cl) } & \multirow[t]{2}{*}{$P$ value } \\
\hline & Yes (\%) & No (\%) & & \\
\hline \multicolumn{5}{|l|}{ Age(in years) } \\
\hline $20-29$ & $2(7.1 \%)$ & $26(92.6 \%)$ & $0.95(0.13-6.98)$ & \\
\hline $30-39$ & $1(1.7 \%)$ & $57(98.3 \%)$ & $0.18(0.02-1.94)$ & 0.53 \\
\hline $40-49$ & $4(6.6 \%)$ & $57(93.4 \%)$ & $0.66(0.13-3.41)$ & \\
\hline$\geq 50$ & $3(10.3 \%)$ & $26(89.7 \%)$ & 1 & \\
\hline \multicolumn{5}{|l|}{ Sex } \\
\hline Male & $7(10.1 \%)$ & $62(89.8 \%)$ & $3.45(0.79-15.05)$ & 0.09 \\
\hline Female & $3(2.8 \%)$ & $104(97.2 \%)$ & 1 & \\
\hline \multicolumn{5}{|c|}{ Types of ART regimen } \\
\hline TDF based & $6(4.8 \%)$ & $119(95.2 \%)$ & $0.86(0.22-3.38)$ & 0.83 \\
\hline AZT based & $4(7.8 \%)$ & $47(92.2 \%)$ & 1 & \\
\hline \multicolumn{5}{|c|}{ CD4 count (cells/mm³) } \\
\hline$<200$ & $5(12.2 \%)$ & $36(87.8 \%)$ & $3.39(0.74-15.63)$ & 0.19 \\
\hline 200-349 & $2(3.8 \%)$ & $51(96.2 \%)$ & $0.96(0.15-6.29)$ & \\
\hline$\geq 350$ & $3(3.6 \%)$ & 79(96.3\%) & 1 & \\
\hline
\end{tabular}


This finding was consistent with several studies, which reported that thrombocytopenia was more prevalent among patients with CD4 count $<200$ cells $/ \mathrm{mm}^{3}[11,17,18]$.

However, the increase in prevalence of thrombocytopenia with decreased CD4 cell count was not statistically significant. This might be due to increase in the frequency of bone marrow abnormalities as the disease progresses [19] and thrombocytopenia is greater in advanced HIV infection [20].

The present study showed that patients on AZT based HAART regimen had a higher prevalence of thrombocytopenia compared to TDF based HAART regimen. Similar to the current finding study done by Suma et al. showed an increment in the prevalence of thrombocytopenia after initiation of Zidovudine [8]. However, thrombocytopenia had not showed statistical significance difference with the type of HAART regimen. The high prevalence of thrombocytopenia might be due to immune mediated destruction of both platelets and megakaryocytes occurs in Zidovudine therapy [8].

\section{Conclusions}

In conclusion, this study has shown that the prevalence of thrombocytopenia after HAART initiation was decreased significantly. HIV patients with old age (age greater than 50 years), lower $\mathrm{CD} 4+\mathrm{T}$ cell count and AZT based HAART regimen had an increased risk of developing thrombocytopenia. Based on our results, a number of study participants still had thrombocytopenia after initiation of HAART. Therefore continuous screening for thrombocytopenia among HIV infected patients should be performed to decrease the risk of morbidity and mortality.

\section{Additional file}

Additional file 1: Questionnaires The data within additional file 1 contains questionnaires, which were used to collect information from the study participants for this study. The questionnaires had two parts; the first part is for collecting data about socio-demographic characteristics of the study subjects. The second part is for collecting data concerning clinical characteristics and immunohematological profiles of the study participants before and after HAART initiation. (DOCX $19 \mathrm{~kb}$ )

\section{Abbreviations}

3TC: Lamivudin; AIDS: Acquired immunodeficiency syndrome; ART: Antiretroviral treatment; AZT/ZDV: Azidothymidine/ Zidovudine; CD4: Cluster of differentiation 4; EVF: Efavirenz; HAART: Highly active antiretroviral therapy; HIV: Human immunodeficiency virus; NVP: Nevirapine; TDF: Tenofovir

\section{Acknowledgments}

The authors would like to extend their deepest appreciation to staff member of ART clinic of Black Lion Specialized Hospital for their cooperation, who providing the necessary information for this study. We also would like to express our thanks for all of the study participants for their cooperation. We are grateful to thank Addis Ababa University for sponsoring this research project.

\section{Funding}

This study was funded by Addis Ababa University with a reference number phy/402/2017. The funders had no role in study design, data collection and analysis, decision to publish, or preparation of the manuscript.

\section{Availability of data and materials}

The datasets used and/or analyzed during the current study are available from the corresponding author on reasonable request.

\section{Authors' contributions}

GGW: Develop proposal and data collection sheet, collected data, analyzed it and wrote the draft of the manuscript. DHW: Conceived the study, supervised the data collection and reviewed the draft of the manuscript. Both authors read and approved the final draft of the manuscript.

\section{Ethics approval and consent to participate}

The study was conducted after ethical letters obtained from Research and Ethics Review Committee of the Department of Medical Physiology, Addis Ababa University, Ethiopia. The research proposal has been submitted to the department of Medical Physiology for review. The departmental research committee (DRC) had reviewed and looked into the originality, feasibility, laboratory setting and ethical aspects of the study. Following through discussion, the committee approved the research proposal developed by the authors with ethical approval reference number phy/219/2016. Then permission was taken from hospital higher management and data was collected after obtaining written informed consent from the study subjects. To keep confidentiality codes were used and unauthorized person didn't have access to the data.

\section{Competing interests}

The authors declare that they have no competing interests.

\section{Publisher's Note}

Springer Nature remains neutral with regard to jurisdictional claims in published maps and institutional affiliations.

\section{Author details}

${ }^{1}$ Department of Medicine, College of Medicine and Health Sciences, Wolkite University, Ethiopia, P.O. Box 07, Wolkite, Ethiopia. ${ }^{2}$ Department of Medical Physiology, School of Medicine, College of Health Sciences, Addis Ababa University, Ethiopia, Addis Ababa, Ethiopia.

Received: 11 July 2017 Accepted: 1 May 2018

Published online: 09 May 2018

\section{References}

1. Kirchhoff F, Silvestri G. Is Nef the elusive cause of HIV-associated hematopoietic dysfunction? J Clin Invest. 2008;118:1622-5.

2. Kumar MB, Thippeswamy $T$, Shankar $R$, et al. Hematological abnormalities in early and advanced HIV infection patients. Int j sci study. 2016;3(11):1-5.

3. Marks KM, Clarke RM, Bussel JB, et al. Risk factors for thrombocytopenia in HIV-infected persons in the era of potent antiretroviral therapy. J Acquir Immune Defic Syndr. 2009;52(5):595-9.

4. Addis Z, Yitayew G, Tachebele B. Prevalence of some hematological abnormalities among HIV positive patients on their first visit to a tertiary health institution in Ethiopia, a cross sectional study. Int Blood Res Rev. 2014;2(6):270-8.

5. Scaradavou A. HIV-related thrombocytopenia. Blood Rev. 2002;16:73-6.

6. Wondimeneh Y, Muluye D, Ferede G. Prevalence and associated factors of thrombocytopenia among HAART naive HIV positive patients at Gondar university hospital, Northwest Ethiopia. BMC research notes. 2014;7(1):1-4.

7. Firnhaber C, Smeaton L, Saukila N, et al. Comparisons of anemia, thrombocytopenia and neutropenia at initiation of HIV antiretroviral therapy in Africa, Asia, and the Americas. Int J Infect Dis. 2010;14(12):e1088-92.

8. Kaza S, Sesank R, Vidyasagar NK, et al. Hematological parameters in HIV subjects on zidovudine therapy. Perspectives med res. 2015;3(2):11-4.

9. Shen Y, Wang J, Wang Z, et al. A cross-sectional study of leukopenia and thrombocytopenia among Chinese adults with newly diagnosed HIV/AIDS. Bioscience trends. 2015;9(2):91-6. 
10. Taremwa IM, Muyindike WR, Muwanguzi E, et al. Prevalence of HIV- related thrombocytopenia among clients at Mbarara regional referral hospital, Mbarara, southwestern Uganda. J blood med. 2015;6:109-13.

11. Enawgaw B, Alem M, Addis Z, et al. Determination of hematological and immunological parameters among HIV positive patients taking HAART and treatment naïve in the antiretroviral therapy clinic of Gondar University hospital, Gondar, Northwest Ethiopia: a comparative cross-sectional study. BMC hematol. 2014;14:8.

12. Woldeamanuel GG, Wondimu DH. Prevalence of anemia before and after initiation of antiretroviral therapy among HIV infected patients at black lion specialized hospital, Addis Ababa, Ethiopia: a cross sectional study. BMC hematol. 2018;18(7):1-7.

13. Miguez-Burbano MJ, Jackson J, Hadrigan S. Thrombocytopenia in HIV disease: clinical relevance, physiopathology and management. Curr Med Chem Cardiovasc Hematol Agents. 2005:3:365-76.

14. Carbonara S, Fiorentino G, Serio G, et al. Response of severe HIV associated thrombocytopenia to highly active antiretroviral therapy including protease inhibitors. J Inf Secur. 2001;42:251-6.

15. Lai SW, Huang CY, Lai HC, et al. Thrombocytopenia and its related factors: a hospital-based cross-sectional study. Ann Acad Med Singap. 2010;39:9-12.

16. Majuf-Cruz A. Changes in blood coagulation in HIV infection. Rev Investig Clin. 1997:49:51-66.

17. Kyeyune R, Saathoff E, Ezeamama AE, et al. Prevalence and correlates of cytopenias in HIV-infected adults initiating highly active antiretroviral therapy in Uganda. BMC Infect Dis. 2014;14:496.

18. Sullivan PS, Hanson DL, Chu SY, et al. Surveillance for thrombocytopenia in persons infected with HIV: results from the multistate adult and adolescent spectrum of disease project. J Acquir Immune Defic Syndr Hum Retrovirol. 1997;14:374-9.

19. Dhurve SA, Dhurve AS. Bone marrow abnormalities in HIV disease. Mediterr J Hematol Infect Dis. 2013;5(1):e2013033.

20. Vannappagari V, Nkhoma ET, Atashili J, et al. Prevalence, severity, and duration of thrombocytopenia among HIV patients in the era of highly active antiretroviral therapy. Platelets. 2011;22(8):611-8.

\section{Ready to submit your research? Choose BMC and benefit from:}

- fast, convenient online submission

- thorough peer review by experienced researchers in your field

- rapid publication on acceptance

- support for research data, including large and complex data types

- gold Open Access which fosters wider collaboration and increased citations

- maximum visibility for your research: over $100 \mathrm{M}$ website views per year 